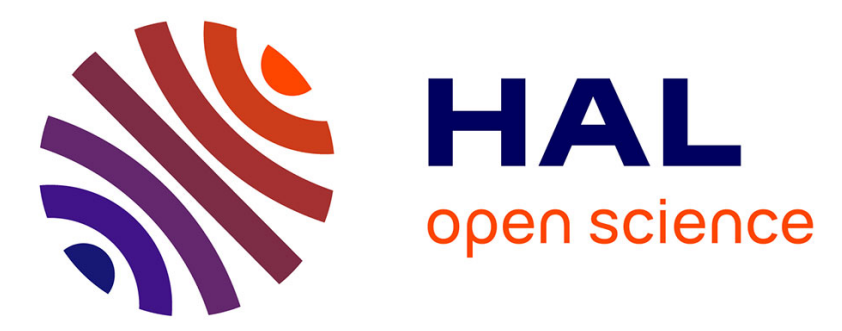

\title{
From music to mathematics and backwards: introducing algebra, topology and category theory into computational musicology
}

Moreno Andreatta

\section{- To cite this version:}

Moreno Andreatta. From music to mathematics and backwards: introducing algebra, topology and category theory into computational musicology. Imagine Math 6 - Mathematics and Culture, Springer, 2018, 10.1007/978-3-319-93949-0_7 . hal-02021952

\section{HAL Id: hal-02021952 \\ https://hal.science/hal-02021952}

Submitted on 10 Dec 2019

HAL is a multi-disciplinary open access archive for the deposit and dissemination of scientific research documents, whether they are published or not. The documents may come from teaching and research institutions in France or abroad, or from public or private research centers.
L'archive ouverte pluridisciplinaire HAL, est destinée au dépôt et à la diffusion de documents scientifiques de niveau recherche, publiés ou non, émanant des établissements d'enseignement et de recherche français ou étrangers, des laboratoires publics ou privés. 


\title{
From music to mathematics and backwards: introducing algebra, topology and category theory into computational musicology ${ }^{1}$
}

\author{
Moreno Andreatta \\ IRCAM - CNRS UMR 9912 STMS - UPMC \\ F-75004 Paris \\ e-mail : Moreno.Andreatta@ircam.fr \\ http://repmus.ircam.fr/moreno \\ \& \\ Invited Researcher at the University of Strasbourg \\ CNRS IRMA UMR 7501 / GREAM / USIAS \\ F-67000 Strasbourg \\ e-mail : andreatta@math.unistra.fr
}

\begin{abstract}
Despite a long historical relationship between mathematics and music, the interest of mathematicians is a recent phenomenon. In contrast to statistical methods and signal-based approaches currently employed in MIR (Music Information Research), the research project described in this paper stresses the necessity of introducing a structural multidisciplinary approach into computational musicology making use of advanced mathematics. It is based on the interplay between three main mathematical disciplines: algebra, topology and category theory. It therefore opens promising perspectives on important prevailing challenges, such as the automatic classification of musical styles or the solution of open mathematical conjectures, asking for new collaborations between

1 This paper provides an overview of the ongoing SMIR (Structural Music Information Research) Project, supported by the University of Strasbourg Institute for Advanced Study and carried on at the Institut de Recherche Mathématique Avancée (IRMA) in collaboration with the GREAM (Groupe de Recherche Expérimentale sur l'Acte Musical) and the Institut de Recherche et Coordination Acoustique/Musique (IRCAM). For a description of the institutional aspects of the project, including the list of participants and past and future events, see the official webpage: http://repmus.ircam.fr/moreno/smir
\end{abstract}


mathematicians, computer scientists, musicologists, and composers. Music can in fact occupy a strategic place in the development of mathematics since music-theoretical constructions can be used to solve open mathematical problems. The SMIR project also differs from traditional applications of mathematics to music in aiming to build bridges between different musical genres, ranging from contemporary art music to popular music, including rock, pop, jazz and chanson. Beyond its academic ambition, the project carries an important societal dimension stressing the cultural component of 'mathemusical' research, that naturally resonates with the underlying philosophy of the "Imagine Maths" conference series. The article describes for a general public some of the most promising interdisciplinary research lines of this project.

\section{Keywords}

Algebra, Topology, Category Theory, Modelling, Computational Musicology, Automatic Classification, Music Information Research, Artificial Creativity, Pedagogy, Mathemusical Research

\section{The "mathemusical" dynamics between music and mathematics (via computer science)}

In western tradition, mathematics and music have been connected for more than 2000 years. Despite this long history of relations between the two fields, the interest of "working mathematicians" in this research domain is a rather new phenomenon. Whilst the power of applying mathematics to music has been acknowledged for a long time, it is only thanks to more recent developments that also music begins to occupy an important place in the development of mathematics. In fact, music has shown to provide a number of difficult theoretical problems, in particular for what concerns their constructive formalization and algorithmic solution. This asks for a permanent feedback between musical thought, mathematical formalisation 
and computational modelling, a dynamic movement between different disciplines that I suggested to call "mathemusical" [3]. This feedback between music and mathematics via computer science is illustrated in the diagram of Figure 1.

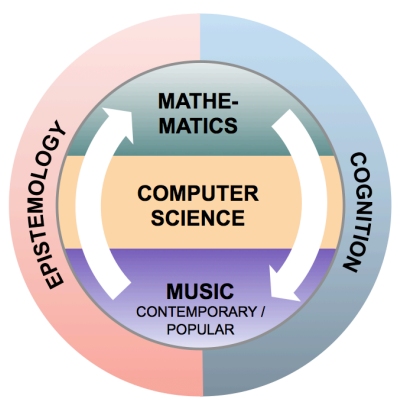

Figure 1: A diagram showing the "mathemusical" dynamics between music and mathematics via computer-science.

Among the music-theoretical problems showing a remarkable link with interesting mathematical constructions and open conjectures, one may quote the following ones that have provided the content of a considerable number of Master and $\mathrm{PhD}$ dissertations: ${ }^{2}$

- Tiling rhythmic canons and their spectral dimensions (via the Fuglede Conjecture)

- Z-relation in music theory and the study of homometric structures in crystallography

- Transformational music theory and the categorical classification of direct musical graphs

- Neo-Riemannian music analysis, spatial computing and Formal Concept Analysis (FCA)

- Diatonic Theory, Maximally Even Sets and the Discrete Fourier Transform

- Periodic sequences and finite difference calculus

\footnotetext{
${ }^{2}$ See http://repmus.ircam.fr/moreno/production for the complete list of students' work focusing on these aspects of the relations between music and mathematics.
} 
- Chord classification and combinatorial block-designs in music composition

Interestingly, most of these problems are deeply interrelated showing the existence of a remarkable interplay between algebraic formalization and geometric representations of musical structures and processes. ${ }^{3}$ Moreover, the mathemusical dynamics (from music to mathematics to music via computer science and the possible epistemological and cognitive implications) constitutes a radical change of perspective with respect to the traditional application of mathematics in the musical domain. Mathemusical problems are characterised by the fact that settling them in an appropriate mathematical framework not only gives rise to new musical applications, but also paves the way to new mathematical constructions. By analysing more carefully the different steps of this mathemusical dynamics, one observes that it can be decomposed into the following three stages:

- Formalization: the initial music-theoretical problem is approached by means of a combination of mathematical tools enabling to formalize it and revealing its computational character

- Generalization: the formalized problem is generalized by using a panoply of mathematical constructions, ranging from abstract algebra to topology and category theory and leading to general statements (or theorems)

${ }^{3}$ This interplay also provides a further example of the duality between temporal and spatial constructions which are the two fundamental ingredients of music according to the field medalist Alain Connes. As he suggested in a conversation with composer Pierre Boulez on the analogy and the difference between the creative processes in mathematics and music: "Concerning music, it takes place in time, like algebra. In mathematics, there is this fundamental duality between, on the one hand, geometry - which corresponds to the visual arts, an immediate intuition - and on the other hand algebra. This is not visual, it has a temporality. This fits in time, it is a computation, something that is very close to the language, and which has its diabolical precision. [...] And one only perceives the development of algebra through music" [15]. 
- Application: once a generalized result has been obtained, it can be applied to music by focusing on one of the three main aspects, i.e. the theoretical, the analytical and the compositional one. ${ }^{4}$

This decomposition of the mathemusical dynamics, together with the triple perspective of the possible musical applications of a general result is shown in Figure 2.

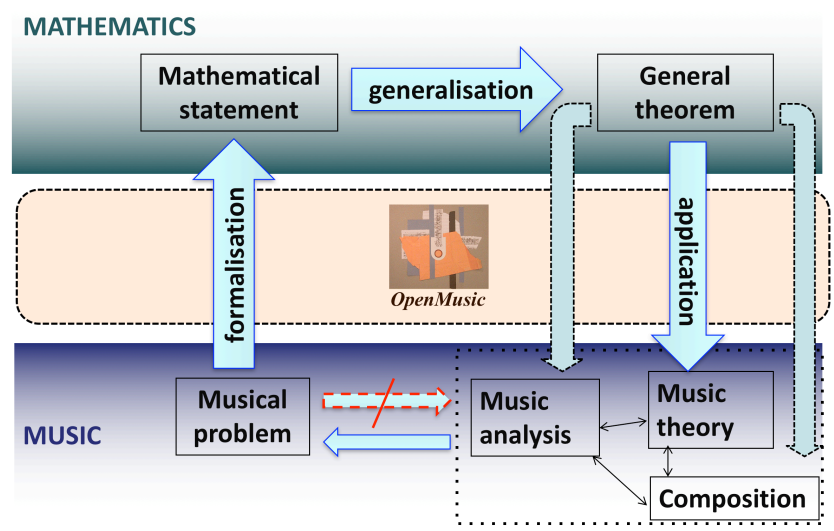

Figure 2: A more detailed perspective on the "mathemusical" research diagram of Fig. 1, with the indication of the three main ingredients of the dynamics (formalisation, generalisation and application). The computer science is represented with the icon of OpenMusic, a visual programming language for computer-aided music theory, analysis and composition currently developed at IRCAM and integrating - in its MathTools environment - most of the computational constructions derived from the "mathemusical" research.

It is this fruitful double movement, from music to mathematics and backwards, which is at the heart of a growing international research activity where computer science is positioned in the middle of this feedback, as an interface for connecting the musical and mathematical domains. We simplify the picture by considering a homogeneous intermediate level corresponding to the place occupied by computer science with respect to music theoretical and

4 As largely documented, these three aspects are deeply interconnected, particularly in Twentieth-Century music and musicology. See [3] for a detailed account of music-theoretical, analytical and compositional applications of the algebraic methods in contemporary music research. 
mathematical research. By analyzing more carefully the different music theoretical problems, one may nevertheless distinguish the cases in which the computer-aided models are directly built in the formalization process as in the case of problems asking for a computational exploration of the solution space, more than a search of a general underlying mathematical theory. To this family belong, for example, typical enumeration problems such as the classification of all possible Hamiltonian paths and cycles within music-theoretical geometric spaces, such as the Tonnetz and their multi-dimensional extensions [7]. Conversely, there are cases in which the computational models are built starting from some general algebraic results, as in the case of the construction of tiling rhythmic canons corresponding to the decomposition of a cyclic group of order $n$ into a direct sum of two non-periodic factors (i.e. two subsets of periodicity equal to $n){ }^{.}$The ubiquitous role of computational modeling in the mathemusical dynamics clearly show that one may balance the usual Leibnizian perspective of music as an exercitium arithmeticae by proposing that also the reverse hypothesis holds, according to which mathematics can be considered, in some special cases, as an exercitium musicae [4].

The new interplay which I propose to establish among algebra, topology and category theory in the service of computational musicology is also necessary to successfully tackle difficult "mathemusical" problems which are linked to open conjectures in mathematics. This is the case of two major problems that have been the object of study in the last fifteen years and which can be approached in a new way: the construction of tiling rhythmic canons and the classification of homometric musical structures. Tiling canons are special rhythmic canons having the property of tiling the time axis by temporal translation of a given rhythmic pattern [6]. This compositional process is deeply connected with an open conjecture in mathematics dating from the 1970s, i.e. Fuglede or "Spectral Conjecture" [5]. This conjecture turns out to be also linked to homometry theory, a field in mathematical combinatorics that originates in crystallography,

${ }^{5}$ See [5] for a description of Tiling Canons as a key to approach open Mathematical Conjectures. 
where one may find crystals having the same X-ray spectrum without being isometric. Analogously, composition naturally provides examples of musical homometric structures having the same distributions of intervals but being not equivalent up to elementary musical transformations such as transpositions or inversions. The deep connection between tiling and homometry comes from the observation that if a rhythmic pattern tiles the musical line by translation (i.e. it generates a tiling rhythmic canon), so does any rhythmic pattern that is homometric to the initial one. Moreover, in this tiling process one only has to consider tiling canons associated to factorizations of a cyclic group as a direct sum of two non-periodic subsets, since all the other canons verify Fuglede's Conjecture [2].

This new perspective on the mathematical relevance of many music-theoretical constructions, with an emphasis on their computational character, probably played an important role in the change of perspective by mathematicians on music and mathematics as a research field. This led in 2007 to the constitution of an international society (the "Society for Mathematics and Computation in Music") ${ }^{6}$ and the launching of the first mathematical Journal devoted to "mathemusical" research (the "Journal of Mathematics and Music", edited by Taylor and Francis). ${ }^{7}$ The recognition of the mathematical dimension of the research carried on in this domain enabled the inscription in 2010 of "Mathematics and Music" as an official research field within the Mathematics Subject Classification of the American Mathematical Society (under the code 00A66). Although the research conducted by the members of this community mainly focused on classical or contemporary art music, there is a growing interest on popular music, whose theoretical problems are often as deep as those belonging to contemporary music. The SMIR project clearly suggests the necessity to push the boundaries between music genres and to look at new possibilities of interaction between contemporary art music and popular music, both providing rich music-theoretical constructions for possible collaborations between mathematicians, computer scientists, musicologists and composers.

\footnotetext{
${ }^{6}$ See http://www.smcm-net.info/

${ }^{7}$ See http://www.tandfonline.com/toc/tmam20/current
} 


\section{The originality of a structural approach in MIR (Music Information Research) ${ }^{8}$}

More specifically, the SMIR project proposes to approach "mathemusical" research by pushing further the fruitful interplay between algebraic computations, topological representations and categorical formalisations. It has two interdisciplinary levels. The first interdisciplinary degree arises within the field of music itself by treating simultaneously, as we have seen, a wide spectrum of different musical genres, ranging from contemporary art music to popular music, including rock, pop, jazz and chanson. Surprisingly, far from being easy to formalize, the compositional process in popular music can be a very rich research domain, particularly once the harmonic structures are represented in a topological way through the formalization of the Tonnetz and their generalized versions as simplicial complexes [14]. Figure 3 shows the construction of the Tonnetz as a simplicial complex starting from the topological representation of notes (0-cells), intervals (1-cells), 3-note chords (2-cells) and their self-assembly by identification of a common edge.

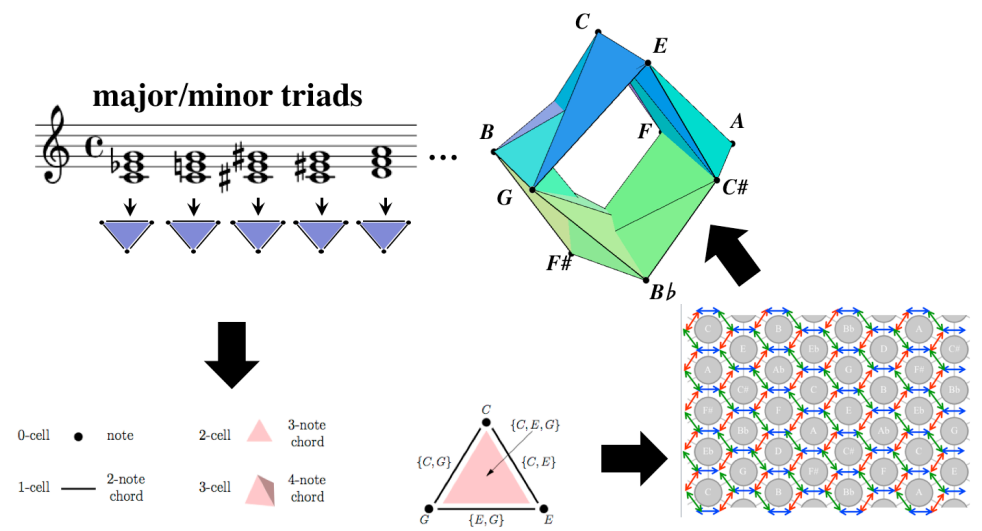

Figure 3. The Tonnetz as a simplicial complex obtained by self-assembly of major and minor chords viewed as 2-cells. See [14].

\footnotetext{
${ }^{8}$ Following the Roadmap described in [41], we prefer to consider MIR as the field of Music Information Research instead of limiting the scope of purely Music Information Retrieval.
} 
The second degree of interdisciplinarity of the project relies in the use of different mathematical concepts in a structural approach which is in contrast to the current state of Music Information Research (MIR), mainly relying on the application of statistical methods in signal processing. Instead of focusing on the signal content, our approach emphasizes the symbolic aspects of musical representations and their structural algebraic, topological and categorical formalisations. For example, a musical chord progression can be seen as a family of subsets of a cyclic or dihedral group, as a path in a simplicial complex space or, in a more abstract way, as a collection of functors and natural transformations. As an example, let us take the generating hexagonal shape of the Tonnetz structure. The simplest way to describe this shape is to consider it as a collection of symmetries relying major and minor chords. More precisely, according to the neo-Riemannian music analysis ${ }^{9}$, there are three ways of transforming a major chord into a minor chord by preserving two common notes and these three symmetries correspond to the $\mathbf{R}, \mathbf{P}$ and $\mathbf{L}$ transformations. The $\mathbf{R}$ transformation (as "relative"), changes for example the $\mathrm{C}$ major chord into the $\mathrm{A}$ minor chord, whereas the $\mathbf{P}$ transformation (as "parallel") and the $\mathbf{L}$ transformation (as "Leading-Tone operator") change respectively the $\mathrm{C}$ major chord into the $\mathrm{C}$ minor and the $\mathrm{E}$ minor chord. In a categorical framework, generalizing the K-net theory (or Klumpenhouwer Networks), the neo-Riemannian transformations are viewed as natural transformations between major and minor chords represented as labelled graphs with vertices corresponding to the notes and arrows corresponding to transposition and inversion

\footnotetext{
9 This approach takes origin in the writings of the German musicologist Hugo Riemann who proposed a "dualistic" perspective of Euler's Tone System [23] based on inversional relations between major and minor chords. After a first algebraic formalisation by David Lewin through the concept of GIS or Generalized Interval System [26], neo-Riemannian theory and analysis has progressively integrated mathematical concepts belonging to topology and algebraic geometry [11] and shown its relevance to the analysis of a popular music repertoire [14].
} 
operations [35]. By definition a transposition by $h$ semi-tons is an operation indicated by $T_{h}$ that sends a generic element $x$ of the cyclic group of order 12 (i.e. a pitch-class in the musical set-theoretical terminology) into $x+h$ (modulo 12). Similarly, one may define the generic inversion operation indicated by $I_{k}$ that sends a pitch-class $x$ into $k$ - $x$ (always modulo 12).
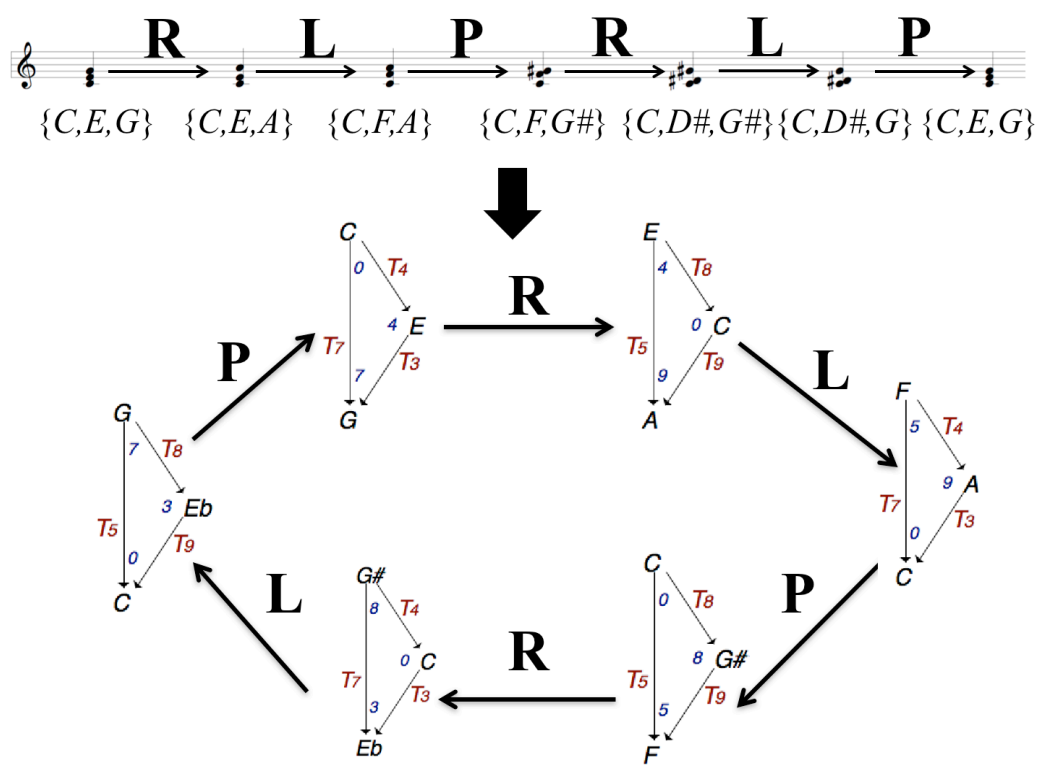

Figure 4. The hexagonal cycle generating the Tonnetz and represented in a categorical framework displaying the transformations between major and minor chords viewed as labelled graphs with vertices corresponding to the notes and arrows corresponding to transposition operations. See [36].

One of the interests of using a categorical approach instead of a group-action based approach in the representation of musical structures such as chords or melodic patterns relies in the possibility to provide a flexible notion of equivalence relation, not necessarily linked to an underlying group action. More precisely, in the usual enumeration and classification of harmonic structures, two chords $A$ and $B$ are considered as equivalent if there exists a musically- 
relevant $^{10}$ group $G$ acting on the family of all possible chord structures (i.e. the family of subsets of the cyclic group of order 12 seen as the space of pitch-classes where the algebraic structure has been forgotten) and such that $A$ and $B$ are related via a transformation $f$ belonging to $G$. Music offers many example where one would feel the need to establish a formal equivalence relation between chords which are not orbits with respect to an underlying group action. The categorical approach ${ }^{11}$ enables precisely to overcome some limitations of the paradigmatic approach by establishing isomorphic relations between configurations of elements (i.e. objects and morphisms between objects) instead of pre-existing "types" of chords. An example is shown in Figure 5 where three chords are "strongly isographic" (i.e. they have the same configuration of arrows) despite the fact that they do not belong to the same orbit under the action of any the three "musically-relevant" groups we mentioned before (cyclic, dihedral and affine groups).

\footnotetext{
${ }^{10}$ To the class of "musically-relevant" groups acting on the family of all possible chords belong groups such as the cyclic group of order 12 (or group of transpositions), the dihedral group of order 24 (or group of transposition and inversions) and the affine group of order 48 (or group of "augmentation", i.e. applications $f$ of the form $f(x)=a x+b$, where $a$ belongs to the set of invertible elements of $\mathbf{Z}_{12}$ and $b$ is any possible transposition factor). By using a term which has a strong philosophical meaning [25], we suggested to call "paradigmatic" a classification approach of musical structures based on an underlying group action [3]. This provides an elegant formalization of the most common chord catalogues, from Anatol Vieru's catalogue of transposition classes of chords [42] to Mazzola/Morris catalogue of affine orbits [27, 31], including Julio Estrada's catalogue of "identities" [17].

${ }^{11}$ Category theory was originally introduced in music theory by Guerino Mazzola in his dissertation Gruppen und Kategorien in der Musik [27] and further extended in Geometrie der Töne [28] and The Topos of Music [29]. For an alternative approach to the categorical formalization of music theory, see Fiore and Noll [18] and our series of papers dealing with the categorical interpretation of Klumpenhouwer Networks, initially within the framework of Topos of Music [30] and, successively, through the set-up of generalized K-nets called "PolyKlumpenhouwer Networks" [35, 36, 37].
} 


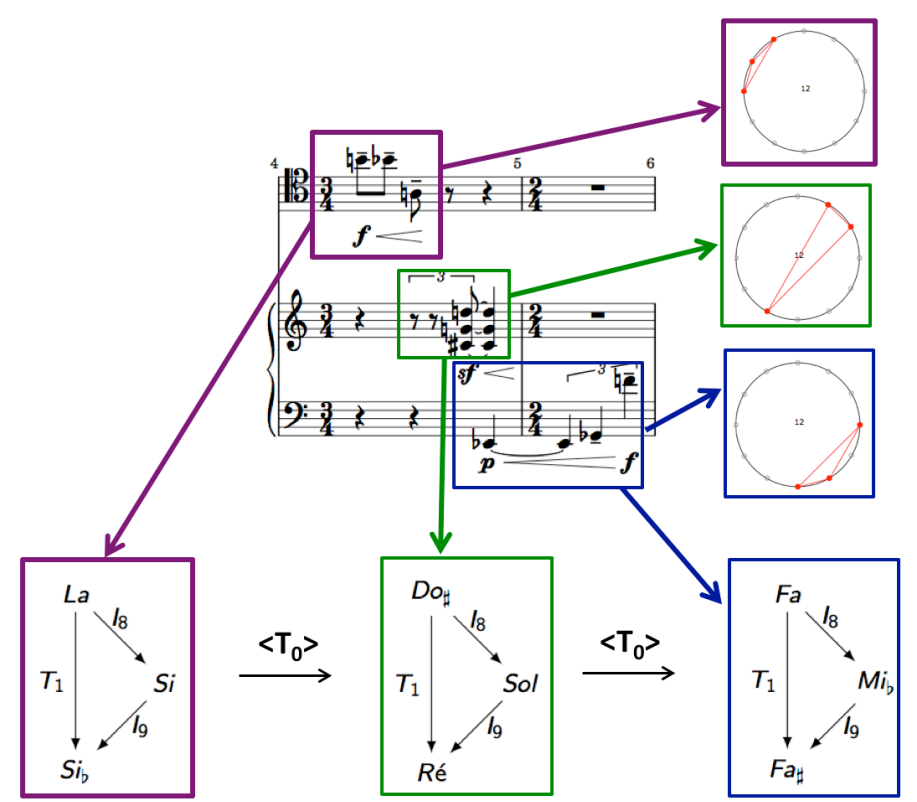

Figure 5. Three chords belonging to Anton Webern's Drei Kleine Stücke, Op. 11/2 which literally share the same type of transpositions and inversions without being in the same orbit under the action of the cyclic, dihedral or affine groups. See [36].

\section{A (very) short journey through some tools and research axes of the SMIR Project}

As we have seen by briefly describing some examples of the interplay between algebraic, topological and categorical approaches, the SMIR project proposes to use structural approaches in Music Information Researches based on advanced mathematics. These approaches include the search of algebraic invariants to classify musical structures, the use of simplicial complexes to represent musical spaces, the use of Galois lattices and ordered structures, together with persistent homological tools and functorial approaches to describe graph-theoretical musical constructions. These theoretical concepts are systematically accompanied by computational modelling including spatial computing, a non-conventional paradigm in computer science aiming to reformulate in spatial terms the data 
structures and their formal manipulations, as in the case of the simplicial representation of the Tonnetz and its possible generalisations. The panoply of tools and theoretical constructions which are potentially useful within a structural approach to music information research can be classified into the three main research axes that will be shortly described in the following sections.

\subsection{The interplay between Mathematical Morphology and Formal Concept Analysis in computational musicology}

By using some recent results that we obtained concerning the connections between topology and Formal Concept Analysis [19], on the one hand, and some existing relations between Mathematical Morphology [40] and Formal Concept Analysis [20] on the other hand [10], the project will investigate how to combine Formal Concept Analysis and Mathematical Morphology in order to approach in a new way some classical problems of Music Information Research. One of the most prominent examples is the automatic retrieval of musical structure. Some promising results have been obtained by Pierre Relaño in his Master dissertation devoted to the application of techniques developed within the field of mathematical morphology to the lattice representation of musical structures, with a special focus on harmony [38].

\subsection{Generalized Tonnetze, Persistent Homology and automatic classification of musical styles}

The SMIR project will build on some recent findings concerning the simplicial complexes and neo-Riemannian music analysis in order to study the problem of automatic classification of musical styles via a purely topological approach based on techniques such as persistent homology, which appears as a fundamental tool in the field of Topological Data Analysis. As in the case of this new research area that emerged from the application of computational topology in data analysis, by computing persistent homology from musical data sets it is possible to characterise the underlying musical space with a 
"topological signature" that reveals its structural properties. Some interesting results have been obtained by Mattia Bergomi in his $\mathrm{PhD}$ dissertation that is the first doctoral thesis devoted to the application of persistent homology to automatic style classification [11]. This approach has been successively applied to a structural computational analysis of popular music [12].

\subsection{Category theory and transformational (computer-aided) music analysis}

Several other "mathemusical" problems emerged in the recent years, which ask for extending the mathematical framework by also including tools and constructions belonging to other fields of mathematics, in particular category theory. As a theory of abstract mathematical structures, category theory is in fact particularly suitable for unifying different music-theoretical constructions. As we have shown, it constitutes the natural mathematical framework for the socalled "transformational music theory" [35]. Following our first attempt at developing a category-based approach to creativity [8], we will explore in this project different categorical constructions at the basis of the creative process in music analysis and composition. As we suggested elsewhere [1], category theory also provides very powerful conceptual tools that can have crucial theoretical implications for cognitive sciences and mathematical psychology. We strongly believe that the fact of coupling an algebraically formalized geometrical approach, such as the transformational one, with a computational perspective has some crucial theoretical implications for cognitive sciences and mathematical psychology. One simple way to have the intuition of this change is to compare the transformational approach in music analysis with some mathematically-oriented directions in developmental psychology and cognition, such as Halford and Wilson's neostructuralistic approach [22], Ehresmann and Vanbremeersch's Model of Memory Evolutive Systems [16] and Phillips and Wilson's Categorical Compositionality [32]. From an epistemological point of view, transformational analysis provides an instantiation, in the music domain, of Gilles-Gaston Granger's ar- 
ticulation between the "objectal" and the "operational" dimensions [21]. This duality was considered by the French epistemologist as the foundational basis for the very notion of "concept" in philosophy. ${ }^{12}$ From the perspective of developmental psychology, among the three problematics which - according to the psychologist Olivier Houdé - mark the renewal of Piaget's genetic epistemology, category theory occupies a central place [24]. Differently from the structural approach which Piaget developed starting from his logical treatise [33] and which also constitutes the conceptual framework of his researches on the "abstraction réfléchissante", category theory introduces, according to Houdé, a new element in the operational thinking. Morphisms enable to take into account an "aspect of logical-mathematical cognition which does not proceed from the transformation of the reality (operations and grouping of operations) but which takes into account the simple relational activity [mise en relation]". ${ }^{13}$ Being capable of integrating these epistemological and cognitive aspects within a theoretical research will be one of the major challenges of the SMIR project. Starting from the reflections of mathematicians on the phenomenological account of contemporary mathematics, and comparing these authors with some more epistemological orientations on the cognitive aspects of the phenomenological method, the structural Music Information Researcher might find the way to constitute a new conceptual space within which some mathematical problems raised by music open new perspectives enabling to enrich the philosophical quest. This would surely lead to a better understanding of the interplay between algebraic formalizations, topological descriptions and categorical representations of musical structures and processes.

\footnotetext{
${ }^{12}$ See, in particular, the article "Contenus formels et dualité", reprinted in [21].

${ }^{13}$ See [24] as well as Piaget's posthumous Morphismes et catégories [34].
} 


\section{REFERENCES}

1. Acotto, E., Andreatta, M., Between Mind and Mathematics. Different Kinds of Computational Representations of Music, Mathematics and Social Sciences, $n^{\circ} 199$, pp. 9$26(2012)$

2. Amiot, E., Music Through Fourier Space: Discrete Fourier Transform in Music Theory, "Computational Music Science" Series, Springer, Heidelberg (2016)

3. Andreatta, M., Méthodes algébriques dans la musique et musicologie du $\mathrm{XX}^{\mathrm{e}}$ siècle: aspects théoriques, analytiques et compositionnels, $\mathrm{PhD}$ thesis in computational musicology, Ecole des hautes études en sciences sociales / IRCAM, Paris (2003)

4. Andreatta, M., Mathematica est exercitium musicae. La recherche 'mathémusicale' et ses interactions avec les autres disciplines, Habilitation Thesis, IRMA/University of Strasbourg (2010)

5. Andreatta, M., Tiling Canons as a key to approach open Mathematical Conjectures?. In E. Chew et al. (eds.), Mathemusical Conversations, Wiley, pp. 86-104 (2016)

6. Andreatta, M., Agon, C. (eds), Special Issue "Tiling Problems in Music", Journal of Mathematics and Music, 3(2), (2009)

7. Andreatta M., Baroin, G., Formal and Computational Models in Popular Music. In Z. Kapoula et al. (eds.), AEsthetics \& Neurosciences: Scientific and Artistic Perspectives, Springer, pp. 257-269 (2016)

8. Andreatta, M., Ehresmann, A., Guitart, R., Mazzola, G.: Towards a categorical theory of creativity. In Yust, J., Wild, J., Burgoyne, J. A. (eds.): MATHEMATICS AND COMPUTATION IN MUSIC 2013, LNCS/LNAI, vol. 7937, pp. 19-37. Springer, Heidelberg (2013)

9. Assayag, G, Rodrigues, J.F., Feichtinger, H. G. eds., Mathematics and Music: A Diderot Mathematical Forum, Springer (2002).

10. Atif, J. Bloch, I., Distel, F., Hudelot, C., Mathematical morphology operators over concept lattices. In Cellier P., Distel F., Ganter B. (eds) Formal Concept Analysis. ICFCA 2013. Lecture Notes in Computer Science, vol. 7880. Springer, Berlin, Heidelberg (2013)

11. Bergomi, M., Dynamical and topological tools for (modern) music analysis, PhD thesis, UPMC/LIM Milan (2015)

12. Bergomi M., Fabbri, F., Andreatta, M., Hey Maths! Modèles formels et computationnels au service des Beatles, Volume! La revue des musiques populaires, G. Tosser, O. Julien (eds.), 161-177 (2015)

13. Bigo L., D. Ghisi, A. Spicher, M. Andreatta, Spatial Transformations in Simplicial Chord Spaces. In Georgaki A., Kouroupetroglou, G. (eds.), Proceedings ICMC/SMC, Athens, Greece, p. 1112-1119 (2014)

14. Bigo, L., Andreatta, M., Topological Structures in Computer-Aided Music Analysis. In Meredith D. (ed.), Computational Music Analysis, Springer, 57-80 (2015).

15. Boulez, P., Connes, A., Creativity in Music and Mathematics. A meeting organized within the Mathematics and Computation in Music Conference at IRCAM (15 June 2011). Video available at: http://agora2011.ircam.fr

16. Ehresmann A. C., Vanbremeersch J.-P., Memory Evolutive Systems: Hierarchy, Emergence, Cognition. Amsterdam: Elsevier (2007)

17. Estrada, J., Théorie de la composition: discontinuum - continuum, PhD thesis, Université de Strasbourg (1994) 
18. Fiore, T., Noll, T.: Commuting Groups and the Topos of Triads. In: Agon, C., Amiot, E., Andreatta, M., Assayag, G., Bresson, J., Mandereau, J. (eds.), MATHEMATICS AND COMPUTATION IN MUSIC 2011, LNCS/LNAI, vol. 6726, pp. 69-83. Springer, Heidelberg (2011)

19. Freund, A., Andreatta, M, Giavitto, J.-L., Lattice-based and Topological Representations of Binary Relations with an Application to Music, Annals of Mathematics and Artificial Intelligence, 73(3-4), 311-334, (2015)

20. Ganter, B. and Wille, R., Formal Concept Analysis: Mathematical Foundations, Springer, Berlin, Heidelberg (1998)

21. Granger G.-G.: Formes, opérations, objets. Paris: Librairie Philosophique J. Vrin (1994)

22. Halford G. S., Wilson W. H.: A category-theory approach to cognitive development, Cognitive Psychology, 12, 356-411 (1980)

23. Hascher, H., Papadopoulos, A. (eds.), Leonhard Euler. Mathématicien, physicien et théoricien de la musique, Editions du CNRS (2015)

24. Houdé O., La référence logico-mathématique en psychologie: entre méthode universelle et rationalité arrogante. In Houdé, O. (ed.), Pensée logico-mathématique, nouveaux objets interdisciplinaires. Paris: Presses Universitaires de France, p. 47-119, (1993)

25. Kuhn, T., The Structure of Scientific Revolutions. University of Chicago Press (1962)

26. Lewin, D.: Generalized Musical Intervals and Transformations. Yale University Press, New Haven (1987)

27. Mazzola, G., Gruppen und Kategorien in der Musik. Hermann (1985)

28. Mazzola, G., Geometrie der Toene, Birkhäuser (1990)

29. Mazzola, G., The Topos of Music, Birkhäuser (2002)

30. Mazzola, G., Andreatta, M.: From a categorical point of view: K-nets as limit denotators, Perspectives of New Music, 44(2), pp. 88-113 (2006)

31. Morris, R., Composition with pitch-classes: a theory of compositional design. New Haven: Yale University Press (1988)

32. Phillips S., Wilson W. H., Categorical Compositionality: A Category Theory Explanation for the Systematicity of Human Cognition, PLoS Computational Biology, 6(7), 114 (2010).

33. Piaget J. Traité de logique, essai de logistique opératoire, Paris, A. Colin (1949).

34. Piaget, J., Henriques, G., Ascher, E., Morphismes et catégories: comparer et transformer. Lausanne: Delachaux et Niestlé (1990).

35. Popoff, A., Andreatta, M., Ehresmann, A.: A Categorical Generalization of Klumpenhouwer Networks. In: Collins, T., Meredith, D., Volk, A. (eds.) MATHEMATICS AND COMPUTATION IN MUSIC 2015, LNCS/LNAI, vol. 9110, pp. 303-314. Springer, Heidelberg (2015).

36. Popoff, A., Agon, C., Andreatta, M., Ehresmann, A.: From K-Nets to PK-Nets: A Categorical Approach. Perspectives of New Music 54(2), 5-63 (2017).

37. Popoff, A., Andreatta, M., Ehresmann, A.: Relational PK-Nets for Transformational Music Analysis. Journal of Mathematics and Music (in press).

38. Relaño, P., Morphologie mathématique, FCA et musicologie computationnelle. Master thesis, ENS-Lyon / LTCI/Télécom ParisTech / LAMSADE, Université Paris Dauphine / IRCAM-CNRS-UPMC, (2017).

39. Schlemmer, T., Andreatta, M., Using Formal Concept Analysis to Represent Chroma Systems. In Yust, J., Wild, J., Burgoyne, J. A. (eds.): MATHEMATICS AND 
COMPUTATION IN MUSIC 2013, LNCS/LNAI, vol. 7937, pp. 189-200, Springer, Heidelberg (2013)

40. Serra, J., Image Analysis and Mathematical Morphology, Academic Press, London, (1982).

41. Serra, X., Magas, M., Benetos, E., Chudy, M., Dixon, S., Flexer, A., Gómez, E., Gouyon, F, Herrera, P., Jorda, S., Paytuvi, O., Peeters, G., Schlüter, J., Vinet, H., Widmer, G., Roadmap for Music Information ReSearch, G. Peeters (ed.), Creative Commons BY-NC-ND 3.0 license, ISBN: 978-2-9540351-1-6 (2013).

42. Vieru, A., Cartea modurilor, 1 (Le livre des modes, 1). Ed. Muzicala, Bucarest (1980). 